\title{
PESQUISAS SOBRE EDUCAÇÃO EM DIREITOS HUMANOS NA AMAZÔNIA AMAPAENSE
}

\author{
Jemina de Araújo Moraes Andrade \\ Helena Cristina Guimarães Queiroz Simões
}

\section{Resumo}

Este estudo pretende analisar quais as tendências investigativas em matéria de Educação em Direitos Humanos (EDH), nas pesquisas da Amazônia amapaense. Entende-se por EDH o processo multidimensional que busca desenvolver práticas sociais e individuais em defesa dos direitos humanos. No âmbito da educação superior, a EDH pode ocorrer, dentre outras formas, por meio da pesquisa, com potencial para orientar políticas públicas e valorizar o reconhecimento da pluralidade social. A pesquisa é documental, baseada nos projetos de pesquisa (2006 a 2018) de uma universidade pública federal. Por meio da análise de conteúdo, duas foram as categorias examinadas: a) gênero, mulheres e pessoas LGBT+; b) grupos raciais, étnicos e identitários. Os resultados revelaram expansão de pesquisas após 2013; maior interesse de docentes mulheres; e inclinação direcionada à área de ciências humanas. As principais tendências de registro voltaram-se para a população indígena. Houve menor opção de pesquisas com foco em pessoas LGBT+ e população ribeirinha.

Palavras-chave: educação em direitos humanos; pesquisa; universidade.

\section{RESEACH ON HUMAN RIGHTS EDUCATION IN THE BRASILIAN AMAZON STATE OF AMAPÁ}

\section{Abstract}

This study intends to analyze the investigative tendencies in themes inherent to Human Rights Education $(\mathrm{EDH})$ in research projects, in the Brazilian Northern Amazon-Amapá State. EDH is understood as the multidimensional process that seeks to the developing social and individual practices for the defense of human rights. In the context of higher education, EDH can occur, among other ways, through research, with the potential to guide public policies and enhance the recognition of socially vulnerable populations. The research is documentary, based on the research projects (2006 to 2018) of a federal public university. Through content analysis, two categories were examined: a) gender, women and LGBT + people; b) racial, ethnic and identity groups. The results revealed an expansion of research after 2013; greater interest from female teachers; and inclination towards the humanities area. The main trends in registration turned to the indigenous population. There was less choice of research focused on LGBT + people and the riverside population.

Keywords: human rights education; research; amazon.

\section{INVESTIGACION SOBRE LA EDUCACION EN DERECHOS HUMANOS EM LA AMAZONIA BRASILENAS EN LE ESTADO AMAPÁ}

Resumen

Este estúdio tiene la intención de analizar cuále sson las tendencias de investigaciónen temas inherentes a la Educación em Derechos Humanos (EDH) em proyectos de investigación, enel Amazonas Amapá. La EDH se entiende como el proceso multidimensional que orienta desarrollo de prácticas sociales e individuales para la defensa de los derechos humanos. En el contexto de la educación superior, la EDH puede ocurrir, entre otras formas, a través de la investigación, con el potencial de orientar las políticas públicas y mejorar el reconocimiento de las poblaciones socialmente vulnerables. La investigación es documental, basada en los proyectos de investigación (2006 a 2018) de una universidad pública federal. A través del análisis de 
contenido, se examinaron dos categorías: a) género, mujeres y personas LGBT +; b) grupos raciales, étnicos e identitarios. Los resultados revelaron una expansión de la investigación después de 2013; mayor interés de las profesoras; e inclinación hacia el área de humanidades. Las principales tendencias en el registro se dirigieron a la población indígena. Hubo menos opciones de investigación centradas en las personas LGBT + y la población ribereña.

Palabras clave: educación en derechos humanos; investigación; universidad.

\section{INTRODUÇÃO}

A educação e os direitos humanos estão intimamente imbricados, pois ambos possuem o papel fundamental de formação e implementação de uma sociedade mais justa e democrática, ao configurarem-se como instrumentos de produção do conhecimento e de superação de violações de direitos da pessoa humana. Assim, a educação voltada aos direitos humanos ganha maior importância quando direcionada ao desenvolvimento humano e de suas potencialidades de modo a efetivar a cidadania plena (ZUCHIWSCHI, 2014).

Em 1993, parte da comunidade internacional, representada por 171 países e 813 organizações governamentais e não-governamentais, reuniu-se na Conferência Mundial de Direitos Humanos, e tratou da importância de uma educação voltada para a compreensão mútua entre as pessoas e o respeito aos direitos. Este encontro influenciou um movimento que culminaria em documentos internacionais e políticas públicas voltados à implementação da chamada Educação em Direitos Humanos (EDH), materializado na Década das Nações Unidas para a Educação na esfera dos Direitos Humanos (1995-2004) e, posteriormente, no lançamento do Programa Mundial para a Educação em Direitos Humanos, a partir de 2005 (SOUZA, 2014).

A partir da influência internacional, o Brasil buscou cumprir com as recomendações e divulgou o Plano Nacional de Educação em Direitos Humanos (PNEDH), em 2006, definindo a EDH como uma ação que deve ser sistemática e multidimensional e que orienta o desenvolvimento dos sujeitos. Esse desenvolvimento deve ser destinado a: conhecimentos históricos sobre direitos humanos; afirmação de valores, atitudes e práticas sociais que expressem a cultura dos direitos humanos em todos os espaços; formação de uma consciência cidadã; desenvolvimento de processos participativos e de construção coletiva; fortalecimento de práticas que gerem a defesa dos direitos humanos e a reparação das suas violações (BRASIL/PNEDH, 2009).

Neste plano há a previsão de desenvolver a EDH em diversos espaços, como na educação não formal, no sistema de justiça e segurança, na mídia, na educação básica e na educação superior. No espaço da educação superior, o seu foco pressupõe um novo modus operandi acadêmico e social, ou seja, a formação de cidadãos, por meio do ensino, pesquisa e extensão, conscientes da sua participação na (re)construção de uma sociedade livre, democrática e igualitária. A ação educativa ali exercida deve contemplar temas transversais contemporâneos como ética, questões de gênero, sexualidade, raça, etnia, opção política, jurisprudência, dentre outros (PNEDH, 2009; ZUCHIWSCHI, 2014).

O PNEDH no eixo da educação superior possui 21 ações programáticas e a de n. 5 recomenda a promoção de "[...] pesquisas em nível nacional e estadual com envolvimento de universidades públicas e privadas, levantando as ações de ensino, pesquisa e extensão em Direitos Humanos, de modo a estruturar um cadastro atualizado e interativo" (BRASIL/PNEDH, 2006, p. 39).

Assim, considerando a política pública da EDH para a educação superior, esta pesquisa coloca como problema: quais as tendências investigativas do(a)s docentes pesquisadore(a)s em temáticas inerentes a educação em direitos humanos? Nosso objetivo, portanto, será mapear os projetos de pesquisa, registrados por docentes, no Departamento de Pesquisa de uma Instituição 
amapaense, entre 2006 (ano de início do PNEDH) e 2018, a fim de analisar os interesses vinculados à área da EDH.

Trata-se de uma pesquisa documental, com análise de conteúdo para o tratamento dos dados (BARDIN, 2011), cujo recorte para este artigo apresentará duas categorias analíticas, quais sejam: a) gênero, mulheres e grupos de pessoas LGBT+; b) grupos raciais, étnicos e identitários.

A pesquisa ocorreu na Universidade Federal do Amapá (UNIFAP), uma universidade pública, localizada no estado do Amapá, extremo norte amazônico brasileiro, que faz fronteira com a Guiana Francesa (Departamento da França) e Suriname. Este território possui uma rica diversidade cultural, social e ambiental (PACHECO, 2012), o que cria um ambiente propício para pesquisas caracterizadas pela multidimensionalidade da $\mathrm{EDH}$.

\section{OS DESAFIOS DAS UNIVERSIDADES NO ÂMBITO DA PESQUISA}

A educação exerce um papel importante na consolidação de uma sociedade mais democrática e plural, recebendo essa missão e responsabilidade social como uma tarefa nada simples. Dentre suas missões, deve atuar para o desenvolvimento equilibrado e integral do individuo, não bastando dispor-se a atender apenas à prescrição das normas em vigor, mas sobretudo atuar visando atender às demandas sociais (AMARAL, CAMARGO, MURTA, 2013).

Para Pimenta e Anastasiou (2010, p. 163) "[...] o processo educativo de qualidade é fruto do envolvimento dos sujeitos nas ações decisórias, o que resulta no fortalecimento de ações organizadas na condução dos projetos e das práticas educativas na universidade". Portanto, a universidade deve se situar como um espaço onde seja possível a manifestação da diversidade e pluralidade de pensamento, “[...] aprofundando suas relações com a sociedade como um todo, superando o período em que esteve a serviço do Estado e das elites" (VIOLA, 2013, p. 33).

O ensino, a pesquisa e a extensão são atividades indissociáveis da vida na universidade, formando um sistema interdependente. E é assim que a pesquisa deve se apresentar como uma atividade aberta de produção em diálogo, cujo fim é o desenvolvimento humano, social e científico (MATOS, 2013).

A Lei de Diretrizes e Bases da Educação Nacional (LDB), ao estabelecer em seu art. 43 sobre as finalidades da educação superior, destaca o papel na pesquisa, caracterizada por

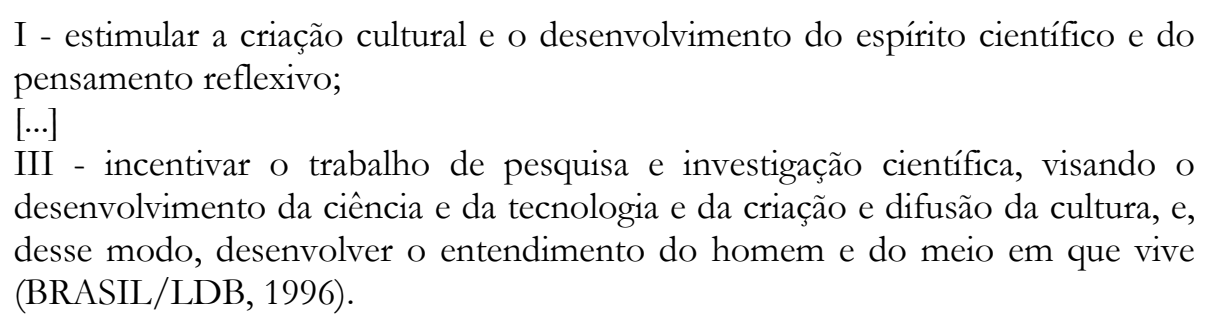
desenvolvimento da ciência e da tecnologia e da criação e difusão da cultura, e, desse modo, desenvolver o entendimento do homem e do meio em que vive (BRASIL/LDB, 1996).

A palavra pesquisa nos passa a ideia de procura feita com cuidado e profundidade. No campo científico, é considerada como "[...] um procedimento formal, com método de pensamento reflexivo, que requer tratamento científico e se constitui no caminho para conhecer a realidade ou para descobrir verdades parciais" (MARCONI, LAKATOS, 2017, p. 169).

Dias e Pequeno (2014, p. 338) caracteriza a pesquisa científica "[...] como um procedimento reflexivo, sistemático, controlado e crítico que nos permite descobrir novos fatos ou dados, relações ou leis, em qualquer campo do conhecimento". Eles também consideram um “[...] procedimento formal que se utiliza de um método para resolver problemas, conhecer a realidade e construir conhecimento. Ela tem como objetivo explicações sobre a realidade" (DIAS, PEQUENO, 2014, p. 338). 
Fica claro, portanto, que a pesquisa é um instrumento fundamental da universidade para a criação e difusão do conhecimento científico, pois, segundo Matos (2013, p. 96) "[...] a ciência tem sua gênese nas necessidades do mundo humano. É uma produção social e cultural. Como tal, deve retornar ao homem oferecendo respostas e instrumentos de transformação de suas situações problematizadas". Logo, nasce das inquietações humanas na tentativa de dar respostas aos mais diversos fenômenos.

A constituição brasileira de 1988 faz referência específica à pesquisa, ao prever um capítulo próprio sobre a Ciência e Tecnologia, com destaque para o art. $218, \ 1^{\circ}$, estabelecendo que "[...] a pesquisa científica básica e tecnológica receberá tratamento prioritário do Estado, tendo em vista o bem público e o progresso da ciência, tecnologia e inovação" (BRASIL, 1988). Desse modo, há um reconhecimento legal por parte do Estado, que a pesquisa, seja básica ou aplicada, é fundamental para o desenvolvimento humano, devendo ser considerada prioridade nas ações do poder público.

Em se tratando das normas infraconstitucionais, a LDB também disciplina e valoriza o papel da pesquisa, apontando em alguns artigos seu estímulo nos ambientes escolares e universitários. $\mathrm{O}$ art. $1^{\circ}$ da lei dispõe que a educação abrange os processos formativos desenvolvidos nas instituições de ensino e pesquisa, e o art. $2^{\circ}$, II, da referida lei, também estabelece dentro dos "Princípios e Fins da Educação Nacional" que o ensino deverá ser ministrado atendendo ao princípio da "[...] liberdade de aprender, ensinar, pesquisar e divulgar a cultura, o pensamento, a arte e o saber".

A LDB define a pesquisa também como um dever do Estado em garantir o “[...] acesso aos níveis mais elevados do ensino, da pesquisa e da criação artística, segundo a capacidade de cada um" (inciso $\mathrm{V}$ do art. $4^{\circ}, \mathrm{BRASIL} / \mathrm{LDB}, 1996$ ). Assim, está posta a intenção do legislador em estimular não só acesso ao conhecimento por meio da pesquisa, mas a liberdade em pesquisar.

Observa-se que, tanto no texto constitucional quanto no infraconstitucional, há uma preocupação em afirmar a importância da pesquisa na educação, especialmente na educação superior, vinculando sua obrigatoriedade nas universidades. A articulação do ensino e extensão ganham força quando nascem da pesquisa, ou seja, "[...] só se aprende, só se ensina, pesquisando; só se presta serviços à comunidade, se tais serviços nasceram da pesquisa [...] e a universidade precisa da pesquisa, para ser mediadora da educação" (SEVERINO, 1996, p. 63).

Nesse sentido, Dias e Pequeno (2014, p. 338) afirmam que o modo como pesquisamos, as preferências metodológicas que optamos, ou seja, o nosso "olhar" sobre os fenômenos, determinam os pressupostos que embasam nossos procedimentos de investigação. Logo, a pesquisa que é realizada serve para entender o mundo a partir das inquietações e das escolhas próprias dos pesquisadores e das pesquisadoras, a partir de seus interesses pessoais e profissionais.

Desse modo, é necessário ter noção que o produto desse conhecimento, ao ser publicizado e se tornar disponível a toda coletividade, assume também um caráter social. Este tem o poder de manter ou modificar determinados processos na vida da comunidade para o qual foi elaborado. Por isso, "[...] a pesquisa traz marcas de intencionalidade dos seus executores, uma vez que está sempre confrontada com elementos de ordem ética, política e social" (DIAS, PEQUENO, 2014, p. 340).

É nesse sentido que abordaremos tais tendências investigativas na educação em direitos humanos, pois quanto maiores forem as proposições científicas para descortinar experiências, saberes, práticas e diagnósticos em espaços/tempos com pouco ou nenhum conhecimento, maior será o acesso aos direitos das populações vulnerabilizadas social e economicamente, e maiores serão as políticas públicas condizentes com as especificidades e diversidades próprias de cada local. 
DOI: $10.12957 /$ teias.\%Y.50132

\title{
O PAPEL DA EDUCAÇÃO EM DIREITOS HUMANOS NA PESQUISA UNIVERSITÁRIA
}

De acordo com a legislação, a educação deve fornecer instrumentos básicos necessários para o exercício da cidadania e, nesse locus, temos na universidade um espaço privilegiado. Todavia, são imprescindíveis diversos elementos para alcançar tais objetivos, dentre eles, um ambiente capaz de garantir educação para todos, com respeito aos direitos humanos e com intuito de evitar as variadas formas de manifestações de injustiça, discriminações, desigualdade e violência, presentes na sociedade, e que se refletem também nos espaços acadêmicos (MATOS, 2013).

Amaral, Camargo e Murta (2013, p. 55) afirmam que "[...] viver os direitos humanos é a melhor forma de aprender e ensinar sobre Direitos Humanos. Não basta educar para os exames dentro das salas de aulas, é preciso educar para a vida". Logo, é necessário conscientizar-se que se educa não apenas para o mercado, mas também e principalmente para as relações que a vida em sociedade nos propicia, nos diversos espaços comunitários (escola, governo, comunidade, família, coletivos etc.), os quais, cada qual a seu modo, possuem importância no processo de convivência mútua.

Viola (2010) faz uma análise tanto da universidade quanto dos direitos humanos, e entende que ambos podem contribuir para reorganizar a sociedade, pois,

\begin{abstract}
enquanto a universidade se constitui como uma exigência do conhecimento e do pensamento, para compreender o universo e o legado da vida - rompendo com as interpretações dogmáticas do mundo -, os direitos humanos surgiram para questionar os privilégios das minorias, dentre elas, os privilégios da aristocracia e o poder absoluto dos reis. Os direitos humanos propunham outro modelo de organização social, baseado na justiça social, equilíbrio político, respeito às divergências e aos conflitos delas decorrentes (p. 34).
\end{abstract}

O desafio para ultrapassar o dogmatismo, a padronização e a hegemonia, que nos submete à supressão de direitos e degradação de pessoas, não é tarefa a curto prazo. No entanto, verificouse um importante movimento iniciado no final do século XX que fortaleceu a pauta dos direitos humanos no mundo e também no Brasil e, por conseguinte, da educação em direitos humanos já neste século XXI, a exemplo do Programa Mundial para Educação em Direitos Humanos (2005); o Plano Nacional de Educação em Direitos Humanos (2006) e as Diretrizes Nacionais para a Educação em Direitos Humanos (2012) (SOUZA, 2014).

Houve um crescimento considerável na América Latina, e também no Brasil onde

os direitos humanos já encontraram local de destaque nas leis e em ações promovidas pelos governos federais, estaduais e municipais, mas ainda há muito por ser feito. Não é fácil mudar todo o contexto histórico, não é fácil mudar formas de pensar e agir, são necessárias ainda muitas atitudes para tornar a inclusão social mais eficaz e "recuperar a consciência do outro, em tempos em que o individualismo se tornou uma marca histórica, é tarefa suficientemente desafiadora para as práticas pedagógicas vigentes" (BITTAR, 2008, p. 327).

Nas concepções do autor, há muitas conquistas, contudo, ainda há muito a ser feito. Diante da conjuntura histórica de negação aos direitos que o Brasil faz parte e ainda carrega - com retrocessos severos na pauta dos direitos humanos, fruto dos novos arranjos político-partidários são necessárias inúmeras medidas para tornar a EDH mais conhecida e eficaz no processo educativo. 
Matos (2013) indica que a EDH é uma área eminentemente interdisciplinar e transdisciplinar e isso ampliaria a compreensão dos direitos humanos como campo de pesquisa na educação superior. Além disso, a universidade pode adotar estratégias para a pesquisa em EDH que podem contribuir para sua implementação e fortalecimento, sendo possível planejar por meio de:

a) $[\ldots]$;

b) indução à atividade de pesquisa na graduação através de programas como, por exemplo, Programa Institucional de Bolsas de Iniciação Científica (PIBIC), ajudando os(as) estudantes a despertar a curiosidade científica debruçando-se em temáticas concernentes aos direitos humanos e, mais precisamente, à educação em direitos humanos;

c) programas de pós-graduação, mestrado e doutorado, criando e/ou fortalecendo linhas de pesquisa interdisciplinares que possibilitem a pesquisa sistemática e profunda em torno dos direitos humanos;

d) criação de espaços institucionais que viabilizem uma ambiência de pesquisa com o surgimento de núcleos e grupos e a adesão de novos(as) pesquisadores(as);

e) $[\ldots]$

f) planejamento institucional da atividade de pesquisa e pós-graduação enfatizando a temática como meta estratégica de seu compromisso em produzir uma ciência que venha a ser de referência social (MATOS, 2013. p. 113-114).

Assim, com base nas concepções do autor, verifica-se algumas das diversas possibilidades para induzir pesquisas em EDH nas instituições, sobretudo nas universidades públicas, e para isso deve-se considerar as opções acima como política institucional a ser incentivada e apoiada.

No entanto, ainda que estudos demonstrem avanços no sistema de normatização e até de implementação das políticas voltadas para a pauta dos direitos humanos e do incentivo em transformá-la numa práxis, a desestruturação promovida pelo governo federal, inerente a estes temas, desarticulou bastante o movimento de indução de tais ações, paralisando-as neste campo, como, por exemplo, a extinção da Secretaria de Educação Continuada, Alfabetização, Diversidade e Inclusão (SECADI) do Ministério da Educação, em 2019, que mobilizava importantes políticas públicas de EDH no Brasil (TAFFAREL, CARVALHO, 2019).

Para Matos (2013), desenvolver pesquisa nas universidades não tem sido tarefa fácil, considerando sua grande complexidade, as exigências corporativas e as demandas sociais e institucionais, especialmente diante da forte tendência para que essas sigam os moldes ou ditames do mercado. Segundo Taffarel e Carvalho (2019, p. 01), as dificuldades ainda têm se agravado frente ao "impasse atual da educação", diante do sucateamento das instituições e órgãos que fazem ciência no Brasil e das "medidas para assegurar as condições de (re)produção do capital".

Escobar (2019) reforça tais dificuldades ao afirmar que, desde 2014, os investimentos em ciência diminuíram no Brasil, agravando a situação em 2019, com a expectativa de anexação de agências de fomento que apoiam a pesquisa e, ainda, redução orçamentária e de financiamento.

Este esvaziamento de incentivos para pesquisas alcança fortemente a consolidação da EDH, uma vez que este campo é recente e ainda estava em fase de estruturação na academia e nas entidades de fomento. Portanto, é necessário repensar os eixos definidores de políticas de investimento para pesquisa no Brasil, principalmente em temáticas que envolvem a dignidade da pessoa humana, uma vez que "[...] a pesquisa em direitos humanos no campo da educação, certamente, poderá não somente integrar mais e mais pessoas, mas também contribuir para 
DOI: $10.12957 /$ teias.\%Y.50132

observarmos atentamente nossa sociedade [...] e apontar caminhos de intervenção (MATOS, 2013, p. 122).

\section{A PESQUISA EM DIREITOS HUMANOS NA UNIVERSIDADE FEDERAL DO AMAPÁ}

$\mathrm{Na}$ perspectiva dos direitos humanos, a pesquisa deve ser pensada como "[...] produção social, em contextos sociopolíticos específicos, sofrendo os impactos do tempo e espaço onde se tecem" (MATOS, 2013, p. 108). E assim, complementa o autor, a ideia da pesquisa em EDH como pesquisa social torna o processo inacabado e permanente, pois sempre possuirá uma carga histórica e refletirá posições frente à realidade. É um campo aberto, “[...] com um foco declarado e decidido na pessoa humana como um ser de direito (MATOS, 2013, p. 112).

A pesquisa apresentada neste artigo é documental, cuja fonte foram os dados públicos de projetos de pesquisa registrados no Departamento de Pesquisa (DPq) da Universidade Federal do Amapá ${ }^{1}$, como formalização das atividades de pesquisa do(a)s docentes. O período delimitado foi de 2006 a 2018. Para o tratamento dos dados foi utilizada a Análise de Conteúdo, baseada em Bardin (2011).

O recorte para este artigo traçou duas categorias analíticas, quais sejam: gênero, mulher(es) e pessoas LGBT+; e grupos raciais, étnicos e identitários. A coleta de dados ocorreu por meio da busca de palavras-chave (no singular e plural) ligadas às temáticas dos direitos humanos (ANDRADE, 2019; PNEDH, 2006), que foram: gênero; mulher; LGBT; lésbica; gay; bissexual; travesti; transgênero; homossexual; raça; étnico-racial; negra(o); etnia; étnica; índio; indígena; populações tradicionais; quilombolas; ribeirinhos.

No total foram encontrados e analisados 48 projetos de pesquisa com as palavras-chave acima, agrupadas nas categorias analíticas apontadas. As análises considerarão gênero d(a)os pesquisador(a)es, distribuição por ano do registro, curso, opções temáticas.

\section{CATEGORIA ANALÍTICA: GÊNERO, MULHER(ES) E PESSOAS LGBT+}

No período delimitado para a pesquisa (2006-2018) e com o recorte para a temática foram encontrados 11 (onze) projetos (Tabela 01). A presença de registros em torno da temática gênero e mulher ocorreu com apenas 08 (oito) projetos, dentro do lapso temporal de doze anos. Sua inserção deu-se a partir de 2009, e seguiu de forma ininterrupta até 2011. Em 2013 contou com 01 (um) projeto, reaparecendo nos anos de 2017 e 2018, com maior frequência. Em relação às pesquisas sobre a população LGBT+, fora localizado 01 registro em 2013; $01 \mathrm{em} 2014$ e $01 \mathrm{em}$ 2018 (um projeto será considerado para a temática de gênero e pessoas LGBT+, por conter as duas palavras-chave).

\footnotetext{
1 A Universidade Federal do Amapá (UNIFAP) foi a primeira instituição pública de ensino superior do estado do Amapá. O início de suas atividades autônomas (antes fora Núcleo Avançado da Universidade Federal do Pará), foi em 1991. Possui quatro campi, nos quais oferta 49 cursos de graduação (presenciais e em EAD). É a única instituição que oferta pós-graduação stricto sensu no estado, atualmente com 15 cursos de mestrado e doutorado (somente um PPG possui mestrado e doutorado). (ANDRADE, 2019).
} 
DOI: $10.12957 /$ teias. $\%$ Y.50132

Tabela 01 - Projetos de pesquisas "gênero, mulher(es) e pessoas LGBT+"

\begin{tabular}{|c|c|c|c|c|}
\hline Autoria & Título do projeto & $\begin{array}{l}\text { Palavras- } \\
\text { chave }\end{array}$ & Curso & Ano \\
\hline $\begin{array}{ll}\text { Manoel de } \\
\text { Jesus de } \\
\text { Souza Pinto }\end{array}$ & $\begin{array}{l}\text { Gênero e Trabalho: feminização da migração na faixa de } \\
\text { fronteira entre o Estado do Amapá e a Guiana Francesa }\end{array}$ & Gênero & $\begin{array}{l}\text { Ciências } \\
\text { Sociais }\end{array}$ & 2009 \\
\hline $\begin{array}{l}\text { Iraci de } \\
\text { Carvalho } \\
\text { Barroso }\end{array}$ & $\begin{array}{l}\text { Violência de gênero contra a mulher no âmbito } \\
\text { doméstico e familiar - uma questão de políticas públicas }\end{array}$ & Gênero & $\begin{array}{l}\text { Ciências } \\
\text { Sociais }\end{array}$ & 2010 \\
\hline $\begin{array}{l}\text { Agripino } \\
\text { Alves Luz } \\
\text { Junior }\end{array}$ & $\begin{array}{l}\text { Atividades físicas de aventura na natureza: } \\
\text { representações sociais dos participantes nas relações } \\
\text { gênero e mídia no Estado do Amapá }\end{array}$ & Gênero & $\begin{array}{l}\text { Educaçã } \\
\text { o Física }\end{array}$ & 2011 \\
\hline $\begin{array}{l}\text { Marcus } \\
\text { Andre de } \\
\text { Souza } \\
\text { Cardoso }\end{array}$ & $\begin{array}{l}\text { Mapeando representações sobre violência e sobre o } \\
\text { trabalho policial: As delegacias especializadas no } \\
\text { atendimento às mulheres (DEAM) a partir do olhar } \\
\text { da(o)s agentes de segurança, das vítimas e dos agressores } \\
\text { no Macapá. }\end{array}$ & Mulheres & $\begin{array}{l}\text { Ciências } \\
\text { Sociais }\end{array}$ & 2013 \\
\hline $\begin{array}{l}\text { Camila } \\
\text { Soares } \\
\text { Lippi }\end{array}$ & $\begin{array}{l}\text { Homossexualidade e Direito Internacional dos Direitos } \\
\text { Humanos }\end{array}$ & $\begin{array}{l}\text { Homossex } \\
\text { ualidade }\end{array}$ & $\begin{array}{c}\text { Relações } \\
\text { Internaci } \\
\text { onais }\end{array}$ & 2013 \\
\hline $\begin{array}{l}\text { José Carlos } \\
\text { Cariacás } \\
\text { Romão dos } \\
\text { Santos }\end{array}$ & $\begin{array}{l}\text { A busca pela exclusão na democracia: Discursos } \\
\text { religiosos contra o direito à cidadania de lésbicas, gays, } \\
\text { transsexuais e transgêneros no Brasil }\end{array}$ & $\begin{array}{l}\text { lésbicas, } \\
\text { gays, } \\
\text { transsexua } \\
\text { is e } \\
\text { transgêner } \\
\text { os }\end{array}$ & $\begin{array}{l}\text { Pedagog } \\
\text { ia }\end{array}$ & 2014 \\
\hline $\begin{array}{l}\text { Evilania } \\
\text { Bento Da } \\
\text { Cunha }\end{array}$ & $\begin{array}{l}\text { Migração de mulheres indígenas para cidade: os desafios } \\
\text { da dupla jornada de trabalho no contexto das etnias } \\
\text { indígenas na fronteira entre Brasil e Guiana Francesa; }\end{array}$ & Mulheres & $\begin{array}{l}\text { Licencia } \\
\quad \text { tura } \\
\text { Intercult } \\
\text { ural } \\
\text { Indígena }\end{array}$ & 2017 \\
\hline $\begin{array}{l}\text { Juliana } \\
\text { Pimenta } \\
\text { Attie }\end{array}$ & $\begin{array}{l}\text { Mulher e Literatura: uma proposta de desconstrução do } \\
\text { cânone literário }\end{array}$ & Mulher & Letras & 2017 \\
\hline $\begin{array}{l}\text { Luciana } \\
\text { Macedo }\end{array}$ & $\begin{array}{l}\text { Análise do papel da mulher na construção de Macapá } \\
\text { durante a formação do território através da fotografia }\end{array}$ & Mulher & $\begin{array}{c}\text { Jornalis } \\
\text { mo }\end{array}$ & 2018 \\
\hline $\begin{array}{l}\text { Ana } \\
\text { Cristina de } \\
\text { Paula } \\
\text { Maues } \\
\text { Soares }\end{array}$ & $\begin{array}{l}\text { Políticas públicas para mulheres na cidade de } \\
\text { Macapá/AP }\end{array}$ & Mulheres & $\begin{array}{c}\text { Relações } \\
\text { Internaci } \\
\text { onais }\end{array}$ & 2018 \\
\hline $\begin{array}{l}\text { Alexandre } \\
\text { Adalberto } \\
\text { Pereira } \\
\end{array}$ & $\begin{array}{l}\text { Educação decolonial: Relação entre interculturalidade, } \\
\text { diversidade sexual e de gênero }\end{array}$ & $\begin{array}{c}\text { Gênero; } \\
\text { sexualidad } \\
\mathrm{e} \\
\end{array}$ & $\begin{array}{c}\text { Artes } \\
\text { Visuais }\end{array}$ & 2018 \\
\hline
\end{tabular}

Fonte: elaborado pelas autoras.

A pauta sobre gênero e mulheres tem encontrado assento garantido nos fóruns e seguimentos voltados para os direitos humanos, e o interesse sobre essa temática tem se acentuado e amadurecido (CARVALHO, RABAY, BRABO, 2008). Os dados desta pesquisa revelam essa tendência quando apontam para um crescimento gradativo, que se acentua nos anos de 2017 e 
DOI: $10.12957 /$ teias.\%Y.50132

2018. Verifica-se o número reduzido de projetos até o ano de 2013, não ultrapassando um registro cadastrado anualmente, e com ausência nos anos de 2012, 2014, 2015 e 2016.

Até 2013, pesquisadores do sexo masculino registraram mais projetos sobre gênero e, entre 2017 e 2018, dos cinco projetos registrados, quatro eram de pesquisadoras.

Ainda que acompanhe a tendência de crescimento, a quantidade de projetos parece bastante tímida. A ampliação das normativas de proteção à mulher, como, por exemplo, a Lei n. 13.104/2015, que altera o código penal para prever o crime de feminicídio como circunstância qualificadora do crime de homicídio, não incentivou registros de projetos sobre o tema no ano de sua publicação, tampouco nos seguintes.

Quanto aos cursos, verifica-se que os interesses possuem relação com as áreas das ciências humanas e sociais, com pesquisas que refletem as questões de gênero e da mulher em diversos contextos, como no território de fronteira - supostamente em função da localização fronteiriça do estado do Amapá com a Guiana Francesa; em atividades físicas; em espaços domésticos; nas representações midiáticas; na construção da história; e na destinação de políticas específicas.

Quanto às pesquisas sobre as pessoas LGBT+, embora se constate algum avanço como a politização do debate sobre o tema e a garantia de direitos fundamentais no âmbito do judiciário, a perspectiva de inclusão dessa população como público de políticas educacionais é tardia, isolada e superficial (MELLO, BRITO, MAROJA, 2012).

No estudo apresentado neste artigo, de 2006 até 2018, foram identificados somente três projetos de pesquisa com a temática LGBT e sexualidade (anos de 2013, 2014 e 2018), com uma lacuna considerável nos anos de 2015, 2016 e 2017. Mott (2003) destaca sua insatisfação com o papel da universidade neste aspecto, ao afirmar que

as Ciências, particularmente as Humanidades, têm a missão crucial de realizar pesquisas e divulgar conhecimentos sólidos visando [...] derrubar os preconceitos e impedir as discriminações [...]. Lastimavelmente, no entanto, raríssimas são as universidades brasileiras que dispõem de áreas de pesquisa e programas voltados aos estudos da (homo)sexualidade em geral e da homossexualidade em particular (p. 165).

Segundo Carvalho; Rabay e Brabo (2008, p. 248), o “[...] reconhecimento político da diversidade sexual e de gênero é um fenômeno recente, precedido pelas lutas dos vários grupos LGBT" e, nesse sentido,

o aprendizado e a prática dos direitos humanos, em particular a inclusão de mulheres e pessoas LGBT como sujeitos de direitos, vêm percorrendo um longo caminho, que passa pelas lutas sociais, legislação e políticas públicas, até se efetivar nas práticas escolares, laboratórios das práticas sociais (CARVALHO, RABAY, BRABO, 2008, p. 250).

Apesar da trajetória de reivindicações ser antiga, seu reconhecimento político e reflexo nas práticas universitárias ainda é considerado novo e às margens, pontuado até hoje por omissões e limitado interesse investigativo. A esse respeito, pode-se supor que as escolhas (ou lacunas) de pesquisa nos espaços da universidade são o reflexo das negações sociais a serem enfrentadas nesse campo.

Dois dos projetos foram coordenados por professores e um por uma professora, vinculados, respectivamente, aos cursos de Pedagogia, Artes Visuais e Relações Internacionais. Temos como maiores interessados, portanto, docentes do sexo masculino e a ligação às áreas das ciências humanas e artes. 
Portanto, na categoria "gênero, mulheres e pessoas LGBT+" foram encontrados alguns registros importantes, mas em número reduzido para a importância social da temática. Para a categoria gênero/mulheres houve $73 \%$ dos registros; para categoria LGBT+ foram $27 \%$. A tendência docente por gênero foi equilibrada, com pequena maioria de mulheres, sendo $45 \%$ de homens e $55 \%$ de pesquisadoras. Todos vinculados a cursos da área de ciências humanas.

Considerando que a análise teve como marcador inicial a publicação em 2006 do PNEDH, até 2018, dividimos o tempo total ao meio (2006-2012; 20013-2018), para verificar se os interesses aumentaram ou diminuíram ao longo dos anos. Nesta categoria, as inclinações para registros de pesquisa aumentaram, pois no primeiro período tivemos $27 \%$ dos projetos formalizados, e, no segundo, $73 \%$.

\section{CATEGORIA ANALÍTICA: GRUPOS RACIAIS, ÉTNICOS E IDENTITÁRIOS}

$\mathrm{Na}$ categoria grupos raciais, étnicos e identitários foram encontrados 37 projetos de pesquisa (Tabela 02). Foram dez registros com as palavras: raça; racial; étnico-racial; negro; negra. Quanto às palavras-chave etnia; étnica; índio e indígena constatou-se 23 projetos. Em relação aos termos populações tradicionais e quilombolas, contou com cinco registros (um em duplicidade com a palavra-chave "racial"), sendo quatro com o termo quilombola e um com o termo populações tradicionais. Não houve achado com a palavra "ribeirinho(a)".

Tabela 02 - Projetos de pesquisas "grupos raciais, étnicos e identitários"

\begin{tabular}{|c|c|c|c|c|}
\hline Autoria & Título do projeto & $\begin{array}{l}\text { Palavras- } \\
\text { chave }\end{array}$ & Curso & Ano \\
\hline $\begin{array}{l}\text { Eugênia da Luz da } \\
\text { Silva Foster }\end{array}$ & $\begin{array}{l}\text { A questão Racial na Escola Pública e } \\
\text { movimentos instituintes }\end{array}$ & Racial & Pedagogia & 2006 \\
\hline $\begin{array}{l}\text { Ricardo Ângelo } \\
\text { Pereira de Lima }\end{array}$ & $\begin{array}{l}\text { Dinâmicas Territoriais em Terras de } \\
\text { Negros no vale do rio Pedreira }\end{array}$ & Negro & Geografia & 2007 \\
\hline $\begin{array}{l}\text { Eugênia da } \text { Luz } \\
\text { Silva Foster e } \\
\text { Márcia } \\
\text { Rodrigues }\end{array}$ & $\begin{array}{l}\text { Questão étnico-racial na escola: } \\
\text { contribuições ao processo de formação } \\
\text { continuada de professores nas escolas do } \\
\text { campo e nas comunidades quilombolas do } \\
\text { Amapá }\end{array}$ & $\begin{array}{l}\text { Étnico- } \\
\text { racial }\end{array}$ & Pedagogia & 2010 \\
\hline $\begin{array}{l}\text { Eugênia da Luz } \\
\text { Silva Foster Prof. } \\
\text { Dr. }^{\text {a }} \text { Márcia Jardim } \\
\text { Rodrigues }\end{array}$ & $\begin{array}{l}\text { Questão étnico-racial na escola: } \\
\text { contribuições ao processo de formação } \\
\text { continuada de professores nas escolas do } \\
\text { campo e nas comunidades quilombolas do } \\
\text { Amapá }\end{array}$ & $\begin{array}{c}\text { Racial- } \\
\text { quilombolas }\end{array}$ & Pedagogia & 2010 \\
\hline Adilson Mendes & $\begin{array}{l}\text { Bens materiais e imateriais da medicina } \\
\text { tradicional dos povos indígenas do } \\
\text { Oiapoque: um mapeamento }\end{array}$ & Indígenas & $\begin{array}{l}\text { Educação } \\
\text { Escolar } \\
\text { Indígena }\end{array}$ & 2010 \\
\hline Kátia Souza Rangel & $\begin{array}{l}\text { Transformações no modo de vida das } \\
\text { populações tradicionais da } \\
\text { Extrativista Cajari (Laranjal do Jarí, } \\
\text { Mazagão e Vitória do Jari-AP). }\end{array}$ & $\begin{array}{l}\text { populações } \\
\text { tradicionais }\end{array}$ & Geografia & 2012 \\
\hline $\begin{array}{l}\text { Jussara de Pinho } \\
\text { Barreiros }\end{array}$ & $\begin{array}{l}\text { A tradição indígena Karipuna: um estudo } \\
\text { da conservação do meio ambiente natural } \\
\text { na aldeia Manga, no município do } \\
\text { Oiapoque }\end{array}$ & Indígena & $\begin{array}{l}\text { Educação } \\
\text { Escolar } \\
\text { Indígena }\end{array}$ & 2012 \\
\hline
\end{tabular}


DOI: 10.12957/teias.\%Y.50132

\begin{tabular}{|c|c|c|c|c|}
\hline $\begin{array}{l}\text { Eugénia da Luz da } \\
\text { Silva Foster }\end{array}$ & $\begin{array}{l}\text { Relações Raciais e Interculturais na Escola: } \\
\text { aproximações entre o Brasil-Amapá e } \\
\text { Cabo-Verde }\end{array}$ & Raciais & Pedagogia & 2013 \\
\hline $\begin{array}{l}\text { Daize Fernanda } \\
\text { Wagner Silva }\end{array}$ & $\begin{array}{l}\text { A construção dos conceitos de pessoa e } \\
\text { pessoalidade nas comunidades indígenas } \\
\text { brasileiras; História e Antropologia em } \\
\text { Fronteiras: presenças indígenas entre } \\
\text { Brasil e Bolívia (1952-2011) }\end{array}$ & Indígena & Direito & 2013 \\
\hline $\begin{array}{l}\text { Antonio Almir } \\
\text { Silva Gomes }\end{array}$ & $\begin{array}{l}\text { Ensino de Línguas e Educação Escolar } \\
\text { Indígena; }\end{array}$ & Indígena & Let & 2014 \\
\hline $\begin{array}{lr}\text { Camila } & \text { Soares } \\
\text { Lippi e Paula de } \\
\text { Carvalho Bastone }\end{array}$ & 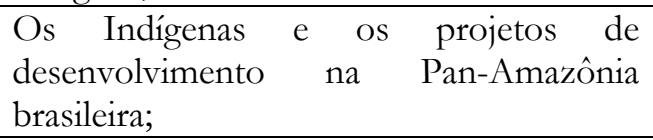 & Indígena & $\begin{array}{c}\text { Relações } \\
\text { Internacion } \\
\text { ais }\end{array}$ & 2014 \\
\hline $\begin{array}{l}\text { Alaan Ubaiara } \\
\text { Brito }\end{array}$ & $\begin{array}{l}\text { Desenvolvimento de Kit Educacional para } \\
\text { Capacitação de Agentes Indígenas em } \\
\text { Sistemas Fotovoltaicos; }\end{array}$ & Indíg & $\begin{array}{l}\text { Engenharia } \\
\text { Elétrica }\end{array}$ & 2014 \\
\hline $\begin{array}{l}\text { Zacarias Alves de } \\
\text { Araújo Neto }\end{array}$ & $\begin{array}{l}\text { Sistemas tradicionais de direito nas terras } \\
\text { indígenas de Oiapoque; }\end{array}$ & Indí & o & 2014 \\
\hline $\begin{array}{ll}\text { Eliane } & \text { Leal } \\
\text { Vasquez - } & \end{array}$ & $\begin{array}{l}\text { O curso de Licenciatura Intercultural } \\
\text { Indígena da Universidade Federal do } \\
\text { Amapá: do marco teórico-filosófico para } \\
\text { sua criação e implantação; }\end{array}$ & Ind & $\begin{array}{l}\text { Licenciatura } \\
\text { Intercultural } \\
\text { Indígena }\end{array}$ & 2014 \\
\hline $\begin{array}{l}\text { Carina Santos de } \\
\text { Almeida }\end{array}$ & $\begin{array}{l}\text { Proteção Tutelar, Assistência e Integração } \\
\text { dos Índios À Sociedade Nacional: Estudo } \\
\text { comparativo da atuação da agência } \\
\text { indigenista do Serviço de Proteção aos } \\
\text { Índios (SPI) entre os povos indígenas do } \\
\text { Brasil meridional e setentrional }\end{array}$ & Ind & $\begin{array}{c}\text { Licenciatura } \\
\text { Intercultural } \\
\text { Indígena }\end{array}$ & 2014 \\
\hline $\begin{array}{ll}\text { Piedade } & \text { Lino } \\
\text { Videira } & \end{array}$ & $\begin{array}{l}\text { O processo de implementação da lei } \mathrm{n}^{\circ} \\
10.693 / 03 \text { em escolas públicas municipais } \\
\text { localizadas ou próximas de comunidades } \\
\text { quilombolas. }\end{array}$ & quils & $\mathrm{Pe}$ & 2014 \\
\hline $\begin{array}{l}\text { Irislane Pereira de } \\
\text { Moraes }\end{array}$ & $\begin{array}{l}\text { Terras de Quilombos no Amapá: } \\
\text { arqueologias, paisagens e patrimônios } \\
\text { quilombolas. }\end{array}$ & quilor & His & 2014 \\
\hline $\begin{array}{l}\text { Giovani José da } \\
\text { Silva }\end{array}$ & $\begin{array}{l}\text { História e Antropologia em Fronteiras: } \\
\text { presenças indígenas entre Brasil e Guiana } \\
\text { Francesa, séculos XX e XXI. }\end{array}$ & Indíg & História & 2015 \\
\hline $\begin{array}{l}\text { Gelsama Mara } \\
\text { Ferreira dos Santos }\end{array}$ & $\begin{array}{l}\text { Acervo digital da memória dos povos } \\
\text { indígenas do Oiapoque. }\end{array}$ & Indígenas & $\begin{array}{l}\text { Licenciatura } \\
\text { Intercultural } \\
\text { Indígena }\end{array}$ & 2016 \\
\hline $\begin{array}{l}\text { David Junior de } \\
\text { Souza Silva }\end{array}$ & $\begin{array}{l}\text { Movimentos Indígenas na Amazônia } \\
\text { Brasileira: Uma Leitura Sociogeográfica. }\end{array}$ & Indíg & $\begin{array}{l}\text { Ciências } \\
\text { Sociais }\end{array}$ & 2016 \\
\hline $\begin{array}{l}\text { Mario Teixeira dos } \\
\text { Santos Neto }\end{array}$ & $\begin{array}{l}\text { Relações entre a ciência moderna ocidental } \\
\text { e os saberes indígenas. }\end{array}$ & Indígenas & Pedagogia & 2016 \\
\hline $\begin{array}{l}\text { Mario Teixeira dos } \\
\text { Santos Neto }\end{array}$ & $\begin{array}{l}\text { Saberes Indígenas: um estudo de caso da } \\
\text { ressignificação do conhecimento. }\end{array}$ & Indígenas & Pedagogia & 2016 \\
\hline $\begin{array}{l}\text { Francisco Otavio } \\
\text { Landim Neto }\end{array}$ & $\begin{array}{l}\text { Cartografia Social, Conflitos Territoriais e } \\
\text { Sustentabilidade: Subsídios para o } \\
\text { planejamento e gestão ambiental na terra }\end{array}$ & Indígena & Geografia & 2017 \\
\hline
\end{tabular}


DOI: $10.12957 /$ teias. $\%$ Y.50132

\begin{tabular}{|c|c|c|c|c|}
\hline & $\begin{array}{l}\text { indígena Uaçá; Etnia Karipuna, Aldeia } \\
\text { Manga, Oiapoque, Amapá, Brasil. }\end{array}$ & & & \\
\hline $\begin{array}{lr}\text { Fernanda } & \text { Matos } \\
\text { Fernandes } & \text { Castelo } \\
\text { Branco } & \end{array}$ & $\begin{array}{l}\text { Consumo de Álcool entre Indígenas da } \\
\text { Etnia Karipuna; }\end{array}$ & Indígenas & Letras & 2017 \\
\hline $\begin{array}{l}\text { Antonio Almir } \\
\text { Silva Gomes }\end{array}$ & $\begin{array}{l}\text { Processos linguísticos de ensino e de } \\
\text { aprendizagem em contextos de Educação } \\
\text { Escolar Intercultural Indígena; }\end{array}$ & Indígena & Letras & 2017 \\
\hline $\begin{array}{l}\text { Carina Santos de } \\
\text { Almeida }\end{array}$ & $\begin{array}{l}\text { Agência indígena e indigenista entre os } \\
\text { povos do Amapá e norte do Pará: estudo } \\
\text { sobre o indigenismo brasileiro no século } \\
\text { XX }\end{array}$ & Indígena & $\begin{array}{l}\text { Licenciatura } \\
\text { Intercultural } \\
\text { Indígena }\end{array}$ & 2017 \\
\hline $\begin{array}{ll}\text { Piedade } & \text { Lino } \\
\text { Videira } & \\
\end{array}$ & $\begin{array}{l}\text { Autoafirmação da Identidade Negra dos } \\
\text { estudantes do Ensino Médio de Macapá }\end{array}$ & Negra & Pedagogia & 2017 \\
\hline $\begin{array}{l}\text { Eugenia Da Luz } \\
\text { Silva Foster }\end{array}$ & $\begin{array}{l}\text { Narrativas De Docentes Negros (As) Que } \\
\text { Atuam Em Cursos De Licenciatura Das } \\
\text { Ies Públicas Do Amapá: Memórias A } \\
\text { Alimentar Práticas Antiracistas }\end{array}$ & Negros & Pedagogia & 2017 \\
\hline $\begin{array}{l}\text { Simone Garcia } \\
\text { Almeida }\end{array}$ & $\begin{array}{l}\text { A representação do negro na literatura } \\
\text { brasileira: caminhos para uma educação } \\
\text { antirracista }\end{array}$ & Negro & História & 2017 \\
\hline $\begin{array}{ll}\text { Alzira } & \text { Marques } \\
\text { Oliveira } & \end{array}$ & $\begin{array}{l}\text { Conhecimento etnobotânico } \\
\text { etnofarmacológico da comunidade negra } \\
\text { de Mazagão Velho, Amapá, Brasil }\end{array}$ & Negra & $\begin{array}{l}\text { Ciências } \\
\text { Ambientais }\end{array}$ & 2017 \\
\hline $\begin{array}{l}\text { Lucineia Alves Dos } \\
\text { Santos }\end{array}$ & $\begin{array}{l}\text { O menino de engenho no fogo morto do } \\
\text { banguê: estudo das teorias raciais na obra } \\
\text { de José Lins do Rego }\end{array}$ & Raciais & Letras & 2018 \\
\hline $\begin{array}{l}\text { Cristiane do } \\
\text { Socorro dos Santos } \\
\text { Nery }\end{array}$ & $\begin{array}{l}\text { Formação de professores indígenas: } \\
\text { história e memória de discentes do CLII - } \\
\text { UNIFAP }\end{array}$ & Indígenas & $\begin{array}{l}\text { Licenciatura } \\
\text { Intercultural } \\
\text { Indígena }\end{array}$ & 2018 \\
\hline $\begin{array}{l}\text { Ramiro Esdras } \\
\text { Carneiro Batista }\end{array}$ & $\begin{array}{l}\text { Dimensão Administrativa da Guerra: } \\
\text { punição, sobrevida e Resistência entre } \\
\text { pessoas e coletivos indígenas do Oiapoque; }\end{array}$ & Indígenas & $\begin{array}{l}\text { Licenciatura } \\
\text { Intercultural } \\
\text { Indígena }\end{array}$ & 2018 \\
\hline $\begin{array}{l}\text { Fabio Rodrigues } \\
\text { Trindade }\end{array}$ & $\begin{array}{l}\text { O envelhecimento e qualidade de vida da } \\
\text { população idosa indígena da etnia karipuna } \\
\text { do estado do Amapá; }\end{array}$ & Indígena & $\begin{array}{c}\text { Enfermage } \\
\mathrm{m}\end{array}$ & 2018 \\
\hline $\begin{array}{l}\text { Samela Ramos da } \\
\text { Silva }\end{array}$ & $\begin{array}{l}\text { A memória da Língua Geral da Amazônia } \\
\text { (Nheengatú) entre os povos indígenas do } \\
\text { baixo Tapajós; }\end{array}$ & Indígenas & Letras & 2018 \\
\hline $\begin{array}{l}\text { Daize Fernanda } \\
\text { Wagner Silva }\end{array}$ & Identidades étnicas em juízo & étnicas & Direito & 2018 \\
\hline $\begin{array}{l}\text { David Junior de } \\
\text { Souza Silva }\end{array}$ & $\begin{array}{l}\text { A formação e a espacialização das } \\
\text { comunidades quilombolas no Amapá: da } \\
\text { colonização à abolição }\end{array}$ & quilombolas & $\begin{array}{l}\text { Ciências } \\
\text { Sociais }\end{array}$ & 2018 \\
\hline
\end{tabular}

Fonte: elaboração das autoras.

No período estudado, constatou-se a presença de registros em torno da temática racial desde 2006 até 2018, mas com lacunas temporais consideráveis entre os registros (2006 a 2010; 2010 a 2013; 2013 a 2017), demonstrando maior interesse de investigar a temática somente após 
2017, cujos registros dobraram (5 dos 10 projetos), inclusive usando a palavra "negro" e "negra", dado pouco observado no decênio anterior (2006-2016).

Observou-se que a maioria dos cursos aos quais os projetos estão vinculados são voltados para a formação de professores (Pedagogia, História, Letras) e provavelmente a demanda surja em decorrência da lei que determinou a inclusão destas temáticas no currículo (Lei n. 10.639/2003), que disciplina o ensino da História e Cultura Afro-Brasileira e Africana, ressaltando a importância do ensino e pesquisa da história e cultura negras, principalmente na formação de formadores. Merece destaque a presença feminina em quase 100\% dos registros de pesquisas (com exceção de apenas um projeto de 2007, registrado por um pesquisador).

Percebe-se, portanto, que o processo de normatização da EDH, como a obrigatoriedade de apresentação de temas ligados aos direitos humanos, legitima e reforça pautas imprescindíveis no contexto educacional, e tem demonstrado resultados positivos de incentivo ao ensino, pesquisa e extensão. Mas, como lembra Ribeiro (2010), há um processo em andamento, em consolidação, "[...] mas ainda inacabado e constantemente colocado à prova" (p. 151).

Ademais, é necessário que a universidade apoie "[...] a criação e fortalecimento de fóruns, núcleos, comissões e centros de pesquisas [...] destinados a promoção, defesa, proteção ao estudo dos direitos humanos", tal como recomenda a ação programática de n. 9 do PNEDH para a educação superior (BRASIL/PNEDH, 2009, p. 40). Quanto às pesquisas sobre quilombolas, verificou-se quatro registros, cujos autores são na maioria mulheres. A distância temporal dos projetos chama atenção, pois um foi registrado em 2010, outros dois somente em 2014 e o último encontrado em 2018. A maior parte dos projetos são vinculados a cursos de formação de professores, a saber: Pedagogia (dois), História (um) e Ciências Sociais - licenciatura (um).

Com o termo populações tradicionais foi encontrado um projeto, registrado por uma pesquisadora do curso de Geografia, no ano de 2012. Para ribeirinho(a) não houve pesquisa registrada. Essa é uma lacuna de pesquisa a ser destacada pois a população amazônica possui como característica numerosos grupos de pessoas que vivem às beiras do rio (os chamados ribeirinhos) e quilombolas, que representam uma diversidade cultural marcante, com histórias e particularidades que precisam ser estudadas para fortalecer o reconhecimento destas populações que fazem parte de nossa história (PACHECO, 2012).

Com efeito, as populações tradicionais, como população quilombolas e ribeirinhas, tantas vezes excluídas das pautas dos direitos humanos, possuem marcas incontestáveis de violência em razão do desconhecimento de sua condição específica enquanto possuidoras de saberes e experiências, que fazem parte do patrimônio cultural imaterial da humanidade (PACHECO, 2012) e, como ato de resistência, também devem ser objeto de interesse de pesquisadores, a fim de fortalecer suas raízes.

Em relação aos termos "etnia, étnica, índio e indígena", foram localizados 23 registros. Nota-se que sobre essa área há um número significativo de projetos de pesquisa, com ocorrências de forma sistemática.

Os resultados expostos na Tabela 02 indicam que a temática indígena apresentou a tendência de maior interesse investigativo no intervalo de doze anos. Embora o primeiro registro localizado tenha ocorrido somente em 2010, em todos os anos, com exceção do ano de 2011, foram registrados projetos de pesquisas neste campo.

Evidencia-se um interesse tanto por pesquisadores (dez homens) quanto por pesquisadoras (onze mulheres) na área, inferindo-se que seja um campo atrativo comum. Podemos citar fatores que parecem determinantes para a maior tendência na escolha: a) o Amapá é um dos estados da Amazônia brasileira com um número importante de terras indígenas homologadas, além de várias etnias originárias do local (GALLOIS, GRUPIONI, 2003); b) fora implantado, em 2010, o campus Binacional de Oiapoque, município do estado do Amapá com cerca de 27,2\% da sua população 
composta por indígenas (IBGE, 2010); c) presença de cursos específicos na área indígena, como Educação Escolar Indígena, Licenciatura Intercultural Indígena; d) grupos de pesquisa e disciplinas direcionadas ao estudo da temática (ex: Direito Indígena na matriz do curso de Direito da UNIFAP).

A política de interiorização das universidades também parece ter favorecido pesquisas com populações próprias dos diferentes cenários brasileiros, e, especificamente na Amazônia, tem fortalecido pesquisas com a temática indígena. Foi o que este estudo mostrou, com o crescimento quantitativo de pesquisas no Campus do Oiapoque, após sua implantação.

Meira e Pankararu (2010, p. 131) dizem que "[...] na visão geral da sociedade, o tema direito indígena não está espontaneamente associado aos direitos humanos". No entanto, cabe ressaltar, que

a pretensão dita "humanitária" de se outorgar direitos humanos aos "índios", ou a qualquer outra minoria explicitamente designada como tal, implica em reconhecer implicitamente que os "índios" e todas as ditas minorias, entre "outras coisas", são também "humanos"; o que na prática significa reconhecer que sua diferença específica se antepõe a universalidade de sua condição humana (DANTAS, 2003, p. 155-156).

No geral, pelos focos das pesquisas, percebeu-se que as abordagens estão ligadas aos direitos humanos, ainda que uns mais diretamente do que outros. $\mathrm{Na}$ categoria "grupos raciais, étnicos e identitários" foram encontrados maior quantidade de projetos em relação à categoria anterior, em especial direcionado à população indígena, com $62 \%$.

As pesquisadoras também foram maioria em optar por projetos direcionados aos temas desta categoria, com $62 \%$ da totalidade, tendo os homens registrado $38 \%$ dos projetos. Temporalmente, no período entre 2013-2018 houve o maior número de registros, 81\%. Cursos vinculados à área de ciências humanas ainda prevalecem, com destaque para as licenciaturas e cursos voltados para formação de professores indígenas.

\section{CONSIDERAÇÕES FINAIS}

A expansão das investigações em direitos humanos no âmbito da educação superior, seguramente, poderá desencadear várias possibilidades de compreender a diversidade social, histórica, cultural e econômica de nossa sociedade. Serve também como um alerta contra as violações à dignidade da pessoa humana e outras (novas) formas de violações. Ademais, apontará caminhos de intervenção e de políticas públicas específicas a partir de dados, diagnósticos, mapeamentos, representações, narrativas que apontem para múltiplas realidades que merecem atenção.

Tão importante quanto a pesquisa por si só é a influência positiva que ela enseja nos espaços a serem pesquisados. A Amazônia possui vasto patrimônio cultural e uma incalculável riqueza ambiental, que por esse mesmo motivo sofre violações de direitos humanos de toda ordem. Por esta razão, merece atenção investigativa peculiar, inclusive com fortalecimento de políticas públicas de pesquisas específicas para este público, neste ambiente.

Os trabalhos analisados abarcam a multidimensionalidade própria da EDH, ao estudar questões de gênero, sexualidade, etnia, raça, que contribuem com muitas respostas para entender a complexidade de sujeitos com experiências, saberes e vivências que podem ser transformadas em conhecimento para compartilhar com o mundo. 
Percebeu-se que as investigações se ampliaram em quantidade a partir de 2013, representando $77 \%$ dos registros de projetos de pesquisa. Docentes mulheres foram maioria na escolha das temáticas, com $60 \%$ de representatividade; além da forte vinculação dos pesquisadores com cursos das áreas de ciências humanas e sociais, especialmente as licenciaturas. Foi possível notar, ainda, que as pesquisas foram se adequando às novas pautas dos diferentes movimentos, com destaque para o maior uso da palavra-chave "negro(a)", por exemplo.

Um destaque é que pesquisas voltadas para algumas populações socialmente vulnerabilizadas, como as pessoas LBGT + e as comunidades ribeirinhas - muito própria da realidade Amazônica - tiveram um número reduzido de projetos em relação aos demais. Isso reflete uma lacuna nas tendências de escolha de pesquisa em EDH pelo(a)s docentes.

Acredita-se, portanto, que os estudos sobre direitos humanos vêm se ampliando na universidade, mas num movimento lento e aquém do esperado. É necessário o incentivo de pesquisas sobre as temáticas ligadas aos direitos humanos para estruturar um importante catálogo de estudos, que subsidiem políticas públicas de redução das violações de direitos da pessoa humana, e ampliar a formação de sujeitos de direito, em especial das populações socialmente excluídas nesta região fronteiriça da Amazônia.

\section{REFERÊNCIAS}

AMARAL, Ana Paula Martins; CAMARGO, Caroline Leite de; MURTA, Eduardo Freitas. Educação em direitos humanos: princípios fundamentais. In: GUTIERREZ, José Paulo; URQUIZA, Antônio H. Aguilera. Direitos Humanos e cidadania: desenvolvimento pela educação em direitos humanos. Campo Grande, MS: Ed. UFMS, 2013, p. 41-64.

ANDRADE, Jemina de Araujo Moraes. Educaşão em direitos humanos na Universidade Federal do Amapá: tendências e lacunas no âmbito da pesquisa e extensão (2006-2018). 214 f. Dissertação (Mestrado em Educação). Universidade Federal do Amapá, Macapá, 2019.

BARDIN, Laurence. Análise de Conteúdo. Revista e ampliada. São Paulo: Edições 70, 2011.

BITTAR, Eduardo C. B. A escola como espaço para emancipação dos sujeitos. In: Zenaide, Maria de Nazaré Tavares et al. Direitos Humanos: capacitação de educadores. João Pessoa: Editora Universitária/UFPB, 2008, v. 2, p. 168-175.

BRASIL. Constituição da República Federativa do Brasil, de 05 de outubro de 1988. Brasília: Subchefia para Assuntos Jurídicos, Casa Civil, Presidência da República, 1988. Disponível em http://www.planalto.gov.br/ccivil_03/constituicao/constitui \%C3\%A7a o.htm. Acesso em 17 set. 2020.

BRASIL. Senado Federal. Lei n. 9.394/1996. Estabelece as Diretrizes e Bases da Educação Nacional LDB. de 20 de dezembro de 1996. Brasília: Subchefia para Assuntos Jurídicos, Casa Civil, $\begin{array}{lllll}\text { Presidência da } & \text { República, } & \text { dasponível } & \text { em }\end{array}$ http://www.planalto.gov.br/ccivil_03/leis/19394.htm. Acesso em 29 jun. 2020.

BRASIL. Congresso Nacional. Lei n. 13.104/2015. Altera o art. 121 do Decreto-Lei n. 2.848, de 7 de dezembro de 1940 - Código Penal, para prever o feminicídio como circunstância qualificadora do crime de homicídio, e 0 art. $1^{\circ}$ da Lei $n$. 8.072, de 25 de julho de 1990, para incluir o feminicídio no rol dos crimes hediondos. Disponível em http://www.planalto.gov.br/ccivil 03/ ato2015-2018/2015/lei/L13104.htm. Acesso em 24 jun. 2020.

BRASIL. Comitê Nacional de Educação em Direitos Humanos. Plano Nacional de Educação em Direitos Humanos - PNEDH. Brasília: Secretaria Especial dos Direitos Humanos; Ministério da Educação, 2006. 
BRASIL. Comitê Nacional de Educação em Direitos Humanos-CNEDH, Ministério da Educação. Plano Nacional de Educação em Direitos Humanos - PNEDH, Brasília: Secretaria Especial dos Direitos Humanos da Presidência da República: MEC, MJ, UNESCO, 2009.

CARBONARI, Paulo César. O sentido dos direitos humanos na educação superior. In: SILVA, Aida Maria Monteiro. (org.). Educação superior: espaço de formação em direitos humanos. São Paulo: Cortez, (Coleção educação em direitos humanos), 2013.

CARVALHO, Maria Eulina Pessoa de; RABAY, Glória; BRABO, Tania Suely Antonelli Marcelino. Direitos Humanos das Mulheres e das Pessoas LGBT: Inclusão da perspectiva da diversidade sexual e de gênero na educação e na formação docente. In: FERREIRA, Lúcia de Fátima Guerra; ZENAIDE, Maria de Nazaré Tavares; DIAS, Adelaide Alves (Orgs.). Direitos Humanos na Educação Superior: Subsídios para a educação em Direitos Humanos na Pedagogia. João Pessoa: Editora Universitária/UFPB, 2008.

DANTAS, Rodrigo de Souza. O “índio" como sujeito político: a democracia zapatista. In: SOUSA JR. José Geraldo de. et al. Educando para os Direitos Humanos Pautas pedagógicas para a Cidadania na Universidade. Universidade Brasília. Editora Síntese Ltda. 2003. Disponível em http://www.dhnet.org.br/memoria/posters/brasil/brasil.html Acesso em 10 fev. 2019.

DIAS, Adelaide Alves; PEQUENO, Marconi José Pimentel. Os fundamentos e as regras essenciais da pesquisa científica em educação em direitos humanos. In: FLORES, Elio Chaves; FERREIRA, Lúcia de Fátima Guerra; BARBOSA E MELO, Vilma de Lurdes (Orgs.). Educação em direitos bumanos e educação para os direitos humanos. João Pessoa: Editora da UFPB, 2014.

ESCOBAR, Herton. Pesquisadores alertam para risco de desmonte da ciência no Brasil. Jornal da USP. Políticas científicas. 11 out. 2019. Disponível em https://jornal.usp.br/universidade/politicascientificas/pesquisadores-alertam-para-risco-de-desmonte-da-ciencia-no-brasil/. Acesso em 30 jan. 2020.

IBGE - Instituto Brasileiro de Geografia e Estatística. Censo Demográfico 1991/2010: Indígenas. Rio de Janeiro: IBGE, 2010. Disponível em https://indigenas.ibge.gov.br/graficos-e-tabelas-2.html. Acesso em 02 mar. 2020.

GALLOIS, D. T.; GRUPIONI, D. F. Povos indigenas no Amapá e Norte do Pará: quem são, onde estão, quantos são, como vivem e o que pensam? São Paulo: Instituto de Pesquisa e Formação em Educação Indígena, Núcleo de História indígena e do indigenismo da Universidade de São Paulo, 2003.

MARCONI, Marina de Andrade; LAKATOS, Eva Maria. Fundamentos de metodologia científica. 8. ed. - [2. Reimpr.]. São Paulo: Atlas, 2017.

MATOS, Junot Cornélio. A educação superior e a pesquisa com foco nos direitos humanos. In: SILVA, Aida Maria Monteiro (Org.). Educaşão superior: espaço de formação em direitos humanos. São Paulo: Cortez, (Coleção em direitos humanos), 2013, p. 95-125.

MEIRA, Marcio Augusto Freitas; PANKARAKU, Paulo. Direitos Humanos e povos indígenas. In: BRASIL. Direitos Humanos: percepções da opinião pública: análises de pesquisa nacional. VENTURI, Gustavo (org.). Brasília: Secretaria de Direitos Humanos, 2010.

MOTT, Luiz. Direitos humanos e cidadania homossexual no brasil: por que os homossexuais são os mais odiados dentre todas as minorias? In: SOUSA JR. José Geraldo de. et al. Educando para os Direitos Humanos Pautas pedagógicas para a Cidadania na Universidade. Universidade Brasília. Editora Síntese Ltda. 2003. Disponível em http://www.dhnet.org.br/memoria/posters/brasil/brasil.html. Acesso em 10 fev. 2019.

PACHECO, Agenor Sarraf. Cosmologias Afroindigenas na Amazônia Marajoara. Projeto História, São Paulo, n. 44, jun. 2012, p. 197-226. 
PENA FILHO, Pio. Reflexões sobre o Brasil e os desafios Pan-Amazônicos. Revista Brasileira de Política Internacional, v. 56, n. 2, Brasília, jul./ dez. 2013.

PIMENTA, Selma Garrido; ANASTASIOU, Léa das Graças Camargo. Docência no ensino superior. $4^{\mathrm{a}}$ ed. São Paulo: Cortez, 2010.

RIBEIRO, Matilde. O enlace entre direitos humanos, superação do racismo e da discriminação racial. In: VENTURI, Gustavo (Org.). Direitos Humanos: percepções da opinião pública: análises de pesquisa nacional. Brasília: Secretaria de Direitos Humanos da presidência da República, 2010.

SEVERINO, Antonio Joaquim. Pesquisa, pós-graduação e universidade. Revista da Faculdade Salesiana, Lorena, v. 24, n. 34, p. 60-68, 1996.

SILVA, Aida Maria Monteiro (Org.). Educaşão superior: espaço de formação em direitos humanos. São Paulo: Cortez, (Coleção em direitos humanos), 2013.

SOUZA, Nair Heloisa Bicalho de. Comitês estaduais de educação em direitos humanos no Brasil: desafios e perspectivas. SILVA, Ana Tereza Reis da (Org.). Leituras críticas em educação e direitos bumanos. Brasília: Liber Livro; Alia opera, 2014.

TAFFAREL, Celi Nelza Zulke. CARVALHO, Marize Souza. A Extinção da SECADI: um golpe fatal nas conquistas no campo da educação. Cadernos GPOSSHE on-line. Dossiê: Crise da educação em tempos de neoconservadorismo. v. 1, n. 1. Fortaleza, 2019, p. 84-90.

VIOLA, Solon Eduardo Annes. Políticas de Educação em Direitos Humanos. In: SILVA, Aida Maria Monteiro; TAVARES, Celma (Org.). Politicas e fundamentos da educação em direitos bumanos. São Paulo: Cortez, 2010.

ZUCHIWSCHI, José. Notas críticas sobre educação em direitos humanos no Brasil. In: SILVA, Ana Tereza Reis da (Org.). Leituras críticas em educação e direitos humanos. Brasília: Liber Livro; Alia opera, 2014.

\section{Informações das autoras}

Jemina de Araújo Moraes Andrade

Instituto Federal de Educação, Ciência e Tecnologia do Amapá (IFAP)

E-mail: jemina.andrade@,ifap.edu.br

ORCID: https://orcid.org/0000-0003-0901-6837

Link Lattes: http://lattes.cnpq.br/2870439712922488

Helena Cristina Guimarães Queiroz Simões

Universidade Federal do Amapá (UNIFAP)

E-mail: simoeshcg@gmail.com

ORCID: https://orcid.org/0000-0002-2170-5574

Link Lattes http://lattes.cnpq.br/5913427639286290 